\title{
Association of B-Type Natriureteric Peptide Levels With Estimated Glomerular Filtration Rate in Different Stages of Chronic Kidney Disease And Relevant Echocardiographic Changes
}

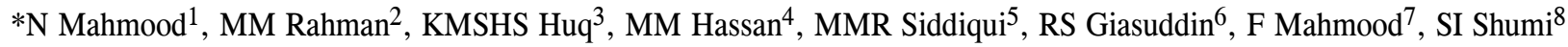

\begin{abstract}
Background: B-type natriuretic peptide (BNP) is a biomarker of cardiovascular disease that is common in patients with chronic kidney disease (CKD). The influence of glomerular filtration rate (GFR) on BNP in CKD may stem from failure to account fully for the effects of coexistent cardiac disease, dysfunction and volume overload.
\end{abstract}

Material \& Methods: This is a cross sectional descriptive type of observational study conducted by the Department of Nephrology of Anwer Khan Modern Medical College Hospital during the period of Jan 2016 to Dec 2016.

Results: A total number of 71 patients were included in the study. Out of them 42(59.15\%) were male and $29(40.85 \%)$ were female with a M:F of 1.45:1. The mean age of the patients was $62.54+13.92$ years (Range 1890 years). Mean e GFR was $21.81+15.01 \mathrm{ml} / \mathrm{min} / 1.73$ body surface area, mean Serum Creatinine was $5.04+3.29 \mathrm{mg} / \mathrm{dl}$, mean $\mathrm{Hb} \%$ was $10.90+1.5 \mathrm{gm} / \mathrm{dl}$ and that of BNP was $1335.03+1838.43 \mathrm{Pg} / \mathrm{ml}$ and that of Ejection Fraction (EF) was 50.05+12.61\%. 21.12\%(15) were on Stage 3 CKD(Chronic Kidney Disease) and $33.80 \%$ (24) and $45.08 \%$ (32) were on Stage-4 and Stage-5 respectively. There was a strong and highly significant inverse association between BNP and e GFR $(\mathrm{p}<0.001)$, with higher BNP level observed in those with lower eGFR. BNP is directly proportional to Serum Creatinine which is significant $(\mathrm{p}<0.001)$. BNP rises as Serum Creatinine rises. Regarding echocardiographic changes, almost all the patients 69(97.18\%) had Left ventricular hypertrophy (LVH). 24(33.80\%) had Left ventricular (LV) diastolic dysfunction, 19(26.76\%) had LV systolic dysfunction and dilated LV and rest of them 28(39.44\%)had good biventricular function. 35 (49.29\%) patients had mild pericardial effusion(PE) and 39(54.92\%) had hypokinesia in different cardiac wall. Most of the patients 65(91.54\%) had mild mitral regurgitation (MR), tricuspid regurgitation (TR), aortic regurgitation (AR).

Conclusion: Our goal was to provide compelling evidence of the association of renal function and BNP, with the full expectation that additional prospective studies will be required to validate and better define this relationship. Ideally, clinicians need clear guidelines regarding BNP and heart failure that include consideration of eGFR. Currently most institutions, including our own, continue to use BNP cutoff diagnostic levels that have not been adjusted for eGFR. Our data emphasized that a single BNP measurement must be evaluated in conjunction with the entire clinical presentation, particularly the level of renal failure.

Key Words: B-type natriuretic peptide (BNP), Estimated Glomerular Filtration Rate (e GFR), Chronic Kidney Disease (CKD)

$1 *$ Dr. Nazneen Mahmood, Associate Professor and Head, Department of Nephrology, Anwer Khan Modern Medical College \& Hospital

${ }^{2}$ Prof. M. Muhibur Rahman, Professor and Head, Department of Nephrology, Sir Salimullah Medical College and Midford Hospital, Dhaka

${ }^{3}$ Prof. KMSH Sirazul Huq, Professor and Head, Department of Cardiology, Anwer Khan Modern Medical College \& Hospital

${ }^{4}$ Prof. Md Mahtabuddin Hassan, Principal and Professor of Medicine, Marine City Medical College and Hospital, Chittagong

${ }^{5}$ Dr. Md Mahmudur Rahman Siddiqui, Associate Professor, Department of Medicine, Anwer Khan Modern Medical College \& Hospital

${ }^{6}$ Dr. Rubayat Sheik Giasuddin, Assistant Professor, Department of Medicine, Anwer Khan Modern Medical College \& Hospital

${ }^{7}$ Dr. Farhana Mahmood, Assistant Professor, Department of Medicine, Chattagram Maa O Shishu Hospital Medical College, Agrabad, Chittagong, Bangladesh

${ }^{8}$ Dr. Shamima Islam Shumi, Biochemist, Ansar and VDP Hospital, Shafipur, Gazipur

*Corresponding Author

Date of submission: 29.10.2017, Date of acceptance: 26.01.2018

AKMMC J 2018; 9(2) : 85-90 


\section{Introduction}

The natriuretic peptide (NP) system is a family of structurally similar but genetically distinct circulatory peptide hormone from either myocardial cell origin (atrial and B-type) or endothelial cell origin (C-type). The NP system functions in the regulation of blood pressure, and electrolyte and volume homeostasis.1Binding of B-type natriuretic peptide (BNP) to its receptors in blood vessels or kidneys initiates diuretic, natriuretic, and vasorelaxant activities. Therefore, the cause of an elevated BNP level is multifactorial in origin and may reflect cardiac dysfunction, and/or changes in renal function. Atrial NP and BNP levels have been proposed as biomarkers for congestive heart failure (CHF), predictors of mortality and biomarkers for drug efficacy in patients with heart failure or left ventricular hypertrophy. ${ }^{2-4}$ Increased mortality in chronic renal failure is most frequently caused by congestive heart failure and/or coronary heart disease. ${ }^{5-7}$ Since renal dysfunction intrinsically was shown to affect BNP levels in some studies, the diagnostic value of BNP levels in the presence of chronic kidney disease has been questioned. ${ }^{7,8}$ Prior studies have involved small patient populations and outcome data reported were variable. Thus, to contribute clinical value, BNP measurements need to be explored within the context of renal function when developing patient treatment strategies. The goal of this study was to further evaluate the relationship between estimated glomerular filtration rate (eGFR) and BNP concentration in a large retrospective cohort of patients with varying levels of renal function

\section{Material and Methods}

This is a cross sectional descriptive type of observational study conducted by the Department of Nephrology of Anwer Khan Modern Medical College Hospital during the period of Jan 2016 to Dec 2016. Intending sample size depending on the coverage of the patient during the study period. Inclusion criteria includes 1. Documentation of a BNP level and a serum creatinine on the same day. 2. $>18$ years of age on test date. 3. Patients presented either as clinic out patients, in the hospital emergency room or were hospital in patients. Exclusion criteria includes patients on RRT (Renal replacement therapy) (on dialysis or transplantation) were excluded from the study.

A detailed history had been taken and physical examination had done. Information on age, gender, body mass index (BMI, calculated as weight divided by square of height), clinic blood pressure, regular medications, and associated comorbidities was recorded. Hypertension and diabetes mellitus were defined as documentation of the diagnosis or use of medications. GFR was estimated using the fourvariable Modification of Diet in Renal Disease (MDRD) formula9 and expressed in $\mathrm{ml} / \mathrm{min}$ per $1.73 \mathrm{~m}^{2}$ BSA. Necessary investigations were carried out and all are recorded on data collection sheet with structured questionnaire. Blood samples were drawn in the morning, all the subject had rested for at least 10 minutes before blood sampling. Venous blood were collected from the anticubital vein of the hand of the patients with minimal stasis without frothing using standard equipment. Serum were collected and were send for biochemical test.

Data were processed and analyzed using computer software SPSS (Statistical Package for Social Science) version 16 . The test statistics were used to analyze the data by descriptive statistics and Chisquare Test. The descriptive statistics are frequency, mean and standard deviation of mean. The data measured on continuous scale were presented as mean and standard deviation from the mean (SDM) were compared using Chi-square Test. Categorical data were expressed as percentages and were evaluated using Chi-square Test. The level of significance is 0.05 . $\mathrm{P}$-value $<0.05$ were considered significant. The summarized information were than presented in the from of tables and charts.

\section{Result}

A total number of 71 patients were included in the study. Out of them $42(59.15 \%)$ were male and 29 $(40.85 \%)$ were female with a $\mathrm{M}: \mathrm{F}$ of $1.45: 1$. The mean age of the patients was $62.54+13.92$ years (Range 18-90 years). Mean e GFR was $21.81+15.01$ $\mathrm{ml} / \mathrm{min} / 1.73$ body surface area, mean Serum Creatinine was $5.04+3.29 \mathrm{mg} / \mathrm{dl}$, mean $\mathrm{Hb} \%$ was $10.90+1.5 \mathrm{gm} / \mathrm{dl}$ and that of BNP was $1335.03+1838.43 \mathrm{Pg} / \mathrm{ml}$ and that of left ventricular ejection fraction (LVEF) was $50.05+12.61 \%$ (Table1). $21.12 \%$ (15) were on Stage 3 CKD (Chronic 
Kidney Disease) and $33.80 \%$ (24) and $45.08 \%$ (32) were on Stage-4 and Stage-5 respectively (Table-2). There was a strong and highly significant inverse association between BNP and e GFR $(\mathrm{p}<0.001)$, with higher BNP level observed in those with lower eGFR (Table-3). BNP is directly proportional to Serum Creatinine (Table-4) which is significant $(\mathrm{p}<0.001)$. BNP rises as Serum Creatinine rises. Regarding echocardiographic changes, almost all the patients $69(97.18 \%)$ had Left ventricular hypertrophy (LVH). 24(33.80\%) had Left ventricular (LV) diastolic dysfunction, 19(26.76\%) had LV systolic dysfunction and dilated $\mathrm{LV}$ and rest of them $28(39.44 \%)$ had good biventricular function. $35(49.29 \%)$ patients had mild pericardial effusion (PE) and 39 (54.92\%) had hypokinesia in different cardiac wall. Most of the patients $65(91.54 \%)$ had mild mitral regurgitation (MR), tricuspid regurgitation (TR), aortic regurgitation (AR) (Table-5).

Table-I: Biochemical parameters of the Patients:

\begin{tabular}{lc}
\hline Biochemical Prameters & Mean+SD \\
\hline eGFR $(\mathrm{ml} / \mathrm{min})$ & $21.81+15.01$ \\
Serum Creatinine(mg/dl) & $5.04+3.29$ \\
Haemoglobin $(\%)$ & $10.90+1.5$ \\
BNP $($ Pg/ml $)$ & $1335.03+1838.43$ \\
LVEF $(\%)$ & $50.05+12.61$ \\
\hline
\end{tabular}

Note: eGFR- estimated glomarular filtration rate, BNP-B-type Natriuretic peptide LVEF-Left ventricular ejection fraction

Table-II: Distribution of Patients according to Staging of CKD:

\begin{tabular}{lcc}
\hline Staging & No & $\%$ \\
\hline Stage-3 & 15 & 21.12 \\
Stage-4 & 24 & 33.80 \\
Stage-5 & 32 & 45.08 \\
Total & 71 & 100.00 \\
\hline
\end{tabular}

Note: CKD- chronic kidney disease
Table-III: Relationship of BNP with eGFR:

\begin{tabular}{|c|c|c|}
\hline BNP & NeGFR & $P$ value \\
\hline $1335.03+1838.43$ & $21.81+15.01$ & $<0.001(\mathrm{~s})$ \\
\hline \multicolumn{3}{|c|}{$\begin{array}{l}\text { Note: BNP- B-type Nat } \\
\text { glomarular filtration rate }\end{array}$} \\
\hline $\begin{array}{l}\text { Table-IV: Rela } \\
\text { Creatinine: }\end{array}$ & onship of BNP & with Serun \\
\hline BNP & Serum Creatinine & $P$ value \\
\hline $1335.03+1838.43$ & $5.04+3.29$ & $<0.001(\mathrm{~s})$ \\
\hline
\end{tabular}

Note: BNP-B-type Natriuretic peptide

Table-V: Distribution of Patients according to Echocardiographic changes:

\begin{tabular}{lcc}
\hline Echocardiographic changes & No & \% \\
\hline LVH & 69 & 97.18 \\
LV diastolic dysfunction & 24 & 33.80 \\
LV systolic dysfunction & 19 & 26.76 \\
and dilated LV & & \\
Good biventricular & 28 & 39.44 \\
Function & & \\
Mild PE & 35 & 49.29 \\
Wall hypokinesia & 39 & 54.92 \\
Mild MR,TR,AR & 65 & 91.54 \\
\hline
\end{tabular}

Note: LVH- left ventricular hypertrophy, LV-left ventricle, MR-mitral regurgitation, TR-tricuspid regurgitation, $A R$ aortic regurgitation

\section{Discussion}

In our study mean age of the patient was $62.54+13.92$ years, whereas in a study of Rajat Tagore et al the mean age was $60+11$ years and that of $63.9+12.3$ years in the study of Takayoshi Tsutamoto et al. ${ }^{10,11}$ Both of which were close to our study. Mean LVEF(left ventricular ejection fraction) in Rajat Tagore et al study was $71+6 \%$, eGFR $38+14 \mathrm{ml} / \mathrm{min} / 1.73 \mathrm{~m}^{2} \mathrm{BSA}$ and median BNP was 59 $\mathrm{Pg} / \mathrm{ml} 10$. And in Takayoshi Tsutamoto et al study mean LVEF was $38.6+11.2 \%$, eGFR $72.1+32.9$ $\mathrm{ml} / \mathrm{min} / 1.73 \mathrm{~m}^{2}$ BSA and BNP $189.8+305 \mathrm{Pg} / \mathrm{ml}^{11}$. In our study mean LVEF was $50.05+12.61 \%$, eGFR $21.81+15.01 \mathrm{ml} / \mathrm{min} / 1.73 \mathrm{~m}^{2}$ BSA and BNP 
$1335.03+1838.43 \mathrm{Pg} / \mathrm{ml}$ which were not similar to their study. Mean BNP was comparatively higher in our study. In the study of Takayoshi Tsutamoto et al mean Serum creatinine was $1.05+0.8 \mathrm{mg} / \mathrm{dl}$, but in our study it was $5.04+3.29 \mathrm{mg} / \mathrm{dl}$ which was different from their study11. It is observed that most of their patients were from stage $3 \operatorname{CKD}(75 \%)$ whereas most of our patients were from stage 5 CKD.

B-type natriuretic peptide belongs to a family of natriuretic proteins whose physiological role is maintenance of sodium homeostasis and protection of the cardiovascular system from volume overload $^{12}$ Studies like the one by Masson et $\mathrm{l}^{13}$ of a cohort of 3916 patients with heart failure, suggested that BNP and NT BNP were independent markers correlating strongly with outcomes of CHF including: mortality, morbidity and hospitalization. Other factors which correlated with BNP levels reported by these authors included age, NYHA class, ventricular function, body mass index, cardiac arrhythmia, ischemia, diurtetics, bilirubin, creatinine, and C-reactive protein. In their study of 213 subjects, Vickery et al 7 were among the first investigators to demonstrate that as renal function declined, BNP levels increased, especially among the subset of patients with Ventricular hypertrophy. In our study most of the patients had LVH in echo cardiogram. De Filippi et al $^{14}$ similarly found that among 389 patients with and without decompensated heart failure, those with eGFR $>60 \mathrm{~mL} / \mathrm{min} / 1.73$ $\mathrm{m}^{2}$ had lower BNP levels than patients whose eGFR $<60 \mathrm{~mL} / \mathrm{min} / 1.73 \mathrm{~m}^{2}$. Outcomes of other studies $^{6,15}$ however, suggested to Tagore et al ${ }^{16}$ that the relationship between renal function and BNP levels may be most strongly dependent on cardiac and volume-related factors. To test this hypothesis, these investigators studied BNP levels in a cohort of 143 clinically euvolemic patients with chronic kidney disease in whom absence of heart disease was clinically validated. These authors concluded that plasma BNP levels were independent of GFR. ${ }^{16}$ Jourdian et $a l^{17}$ evaluated use of serial measures of BNP over time to evaluate response to angiotensin converting enzyme inhibitors, beta blockers and diuretics and demonstrated the potential utility of these measures in predicting death or hospitalization related to chronic heart failure. These authors excluded patients with chronic renal failure from their study. ${ }^{17}$ Suresh and Farrington ${ }^{18}$ conducted a study of BNP levels in dialysis patients and concluded that BNP levels were predictive of presence of left ventricular dysfunction, cardiac events and survival in the presence of end stage renal disease, suggesting that BNP levels may be informative across the full range of renal function and even in its absence.

Mark et $a l^{19}$ also performed a study for which they recruited patients to cover a range of renal function including patients on hemodialysis $(n=55)$, with functional renal allografts $(n=53)$ and 188 patients separated into quartiles based on renal function as determined by creatinine clearance measures. Patients were further evaluated for heart function by echocardiography for presence of left ventricular hypertrophy, dilatation, systolic and/or diastolic dysfunction, pharmacological treatment and blood chemistry. These authors concluded that, across the spectrum of renal function represented in their population, GFR exceeded ventricular function as the more important determinant impacting serum BNP levels. These authors further noted that in addition to GFR, hypoalbuminemia, anemia, use of beta blockers and age were significant confounders of serum BNP levels as has also been reported by others. ${ }^{20-24}$ Although subgroups of the Mark et al ${ }^{18}$ study were small, the authors cautioned that diagnostic utility of BNP in the presence of deteriorating renal function may be compromised to some extent.

In the present study, BNP was modeled as a function of eGFR and CHF classification. Differences in the relationship of BNP with eGFR in the presence and absence of CHF were explored. Patients with diagnostic codes for end stage renal disease, renal transplants or those on dialysis were excluded from these analyses to allow for evaluation in the presence of varying degree of renal function. Our data corroborated that a strong and highly significant inverse association between BNP and eGFR $(\mathrm{P}<0.001)$ was evident, with higher BNP levels observed as eGFR declined. In addition our study demonstrated that increasing severity of underlying congestive heart failure was associated with increasing BNP $(\mathrm{P}<0.001)$. In the study of Carmen L Wiley et al, ${ }^{25} 2009$, also showed that there was higher BNP levels as eGFR declines.

Several investigators indicated that elevated BNP 
concentrations can result from renal failure. ${ }^{6,7,26}$ Our results confirmed previous studies that concentrations were progressively higher in patients with progressively more advanced CKD, especially in patients with an eGFR of less than $60 \mathrm{~mL} / \mathrm{min} / 1.73$ $\mathrm{m}^{2}$ (CKD stage III). Decreased renal clearance raises BNP. The previous experimental study conducted by Vickery et $a l^{7}$ showed that NT-pro BNP was affected more than BNP with progression of CKD. One must consider renal function along with sex and LVEF when using BNP or NT-pro BNP as a cardiac biomark-er. Takami et $a l^{6}$ found that patients with renal impairment had a greater level of serum BNP than patients with hypertension and normal renal function. Failure to consider renal status limits the diagnostic capabilities of BNP and NT-pro BNP. ${ }^{19}$ The effect of renal disease differs by sex. In most cases, BNP and NT-pro BNP are increased by stage III for women, whereas for men at stage III, the peptide concentrations are still fairly close to stage I, except for men with moderately deficient LVEF (35\%-50\%).

Current literature has supported clear and convincing evidence of increasing BNP levels with worsening heart failure, but has lacked clear recommendations regarding renal function. Understanding the relationship of eGFR and BNP in the presence and absence of clinical heart failure is beneficial to clinicians' understanding and interpretation of BNP levels when making diagnostic and treatment decisions.

\section{Conclusion}

Our goal was to provide compelling evidence of the association of renal function and BNP, with the full expectation that additional prospective studies will be required to validate and better define this relationship. Ideally, clinicians need clear guidelines regarding BNP and heart failure that include consideration of eGFR. Currently most institutions, including our own, continue to use BNP cutoff diagnostic levels that have not been adjusted for eGFR. Our data emphasized that a single BNP measurement must be evaluated in conjunction with the entire clinical presentation, particularly the level of renal failure.

Conflict of interest: We have no conflict of interest.

\section{References}

1. Levin ER, Gardner DG, Samson WK. Natriuretic peptides. N Engl J Med 1998; 339: 321-328.

2. Burnett JC, Kao PC, Hu DC et al. Atrial natriuretic peptide elevation in congestive heart failure in the human. Science 1986; 231: 11451147.

3. Yamada Y, Goto J, Yokota M. Brain natriuretic peptide is a sensitive indicator of impaired leftventricular function in elderly patients with cardiovascular disease. Cardiology 1997; 88: 401-407.

4. Yamamoto K, Burnett JC Jr, Jougasaki M et al. Superiority of brain natriuretic peptide as a hormonal marker of ventricular systolic and diastolic dysfunction and ventricular hypertrophy. Hypertension 1996; 28: 988-994.

5. Schaubel DE, Parsons DA, Hall NI et al. The Canadian Organ Replacement Register on renal replacement therapy. Nephrol News Issues 1997; 11: 23-24, 35.

6. Takami Y, Horio $\mathrm{T}$, Iwashima $\mathrm{Y}$ et al. Diagnostic and prognostic value of plasma brain natriuretic peptide in non-dialysis-dependent CRF. Am J Kidney Dis 2004; 44: 420-428.

7. Vickery S, Price CP, John RI et al. B-type natriuretic peptide (BNP) and amino-terminal proBNP in patients with CKD: relationship to renal function and left ventricular hypertrophy. Am J Kidney Dis 2005; 46: 610-620.

8. Mueller C, Laule-Kilian K, Scholer A et al. Btype natriuretic peptide for acute dyspnea in patients with kidney disease: insights from a randomized comparison. Kidney Int 2005; 67: 278-284.

9. Levey AS, Coresh $\mathrm{J}$, Greene $\mathrm{T}$ et al. Using standardizedserum creatinine values in the modification of diet in renal disease study equation for estimating glomerular filtration rate. Ann Intern Med. 2006; 145: 247-254

10. Rajat Tagore, Lieng H Ling, Hong Yang et al. Natriuretic Peptides in Chronic Kidney Disease. Clin J Am Soc Nephrol 2008; Nov 3(6): 16441651. 
11. Takayoshi Tsutamoto, Hiroshi Sakai, Chitose Ishi Kawa et al. Relationship Between Renal Function and Plasma Brain Natriuretic Peptide in Patients with Heart Failure. Journal of the American College of Cardiology. 2006; 47(3): 582-587.

12. Daniels LB, Maisel AS. Natriuretic peptides. J Am Coll Cardiol. 2007; 50: 2357-2368.

13. Masson S, Latini R, Anand IS et al. Direct comparison of B-Type natriuretic peptide (BNP) and amino terminal proBNP in a large population of patients with chronic and symptomatic heart failure: the Valsartan Heart Failure (Val-HeFT) Data. Clin Chem 2006; 52: 1528-1538.

14. deFilippi CR, Seliger SL, Maynard S et al. Impact of renal disease on natriuretic peptide testing for diagnosing decompensated heart failure and predicting mortality. ClinChem 2007; 53: 1511-1519.

15. Zoccali C, Mallamaci F, Benedetto FA et al. Cardiac natriuretic peptides are related to left ventricular mass and function and predict mortality in dialysis patients. J Am Soc Nephrol 2001; 12: 1508-1515.

16. Tagore $\mathrm{R}$, Ling LH, Yang $\mathrm{H}$ et al. Natriuretic peptides in chronic kidney disease. Clin J Am Soc Nephrol 2008; 3: 1644-1651.

17. Jourdain P, Jondeau G, Funck F et al. Plasma brain natriuretic peptide-guided therapy to improve outcome in heart failure: the STARSBNP Multicenter Study. J Am Coll Cardiol 2007; 49: 1733-1739.

18. Suresh M, Farrington K. Natriuretic peptides and the dialysis patient Semin Dial 2005; 18: 409-419.

19. Mark PB, Stewart GA, Gansevoort RT et al. Diagnostic potential of circulating natriuretic peptides in chronic kidney disease. Nephrol Dial Transplant 2006; 21: 412-410.
20. Davis ME, Richards AM, Nicholls MG et al. Introduction of metoprolol increases plasma Btype cardiac natriuretic peptides in mild, stable heart failure. Circulation 2006; 113: 977-985

21. van den Meiracker AH, Lameris TW, van de Ven LL et al. Increased plasma concentration of natriuretic peptides by selective beta1-blocker bisoprolol. J Cardiovasc Pharmacol 2003; 42: 462-468.

22. Lukowicz TV, Fischer M, Hense HW et al. BNP as a marker of diastolic dysfunction in the general population: Importance of left ventricular hypertrophy. Eur J Heart Fail 2005; 7: 525-531.

23. Kanda $\mathrm{H}$, Kita $\mathrm{Y}$, Okamura $\mathrm{T}$ et al. What factors are associated with high plasma B-type natriuretic peptide levels in a general Japanese population? J Hum Hypertens 2005; 19: 165172.

24. Tsuji H, Nishino $\mathrm{N}$, Kimura $\mathrm{Y}$ et al. Haemoglobin level influences plasma brain natriuretic peptide concentration. Acta Cardiol 2004; 59: 527-531.

25. Carmen L. Wiley, Sean P. Switzer, Richard L. Berg et al. Association of B-Type Natriuretic Peptide Levels With Estimated Glomerular Filtration Rate and Congestive Heart Failure.Clinical Medicine and Research 2009; 8(1): 7-12.

26. McCullough PA, Due P, Omland T, et al. Btype natriuretic peptide and renal function in the diagnosis of heart failure: an analysis from the Breathing Not Properly Multinational Study. Am J Kidney Dis. 2003; 41: 571-579. 